\title{
Coaching and barriers to weight loss: an integrative review
}

This article was published in the following Dove Press journal:

Diabetes, Metabolic Syndrome and Obesity:Targets and Therapy

23 December 2016

Number of times this article has been viewed

\section{Karen Fernanda Muñoz Obino' \\ Caroline Aguiar Pereira' \\ Rafaela Siviero \\ Caron-Lienert ${ }^{2}$}

'Nutrology/Clinical Nutrition Unit, Ernesto Dornelles Hospital, ${ }^{2}$ Nutrition of the Educational and Research Institute of Moinhos de Vento Hospital, Porto Alegre, Brazil

Correspondence: Karen Fernanda Muñoz Obino

Nutrology/Clinical Nutrition Unit, Ernesto Dornelles Hospital, Avenida Ipiranga, I80I - Porto Alegre - RS, 90160-092, Brazil

Email karenfmunoz@gmail.com
Introduction: Coaching is proposed to raise a patient's awareness and responsibility for their health behaviour change by transforming the professional-patient relationship.

Objective: To review the scientific literature on how coaching can assist in weight loss and improve a patient's state of health.

Methodology: An integrative literature search was performed using PubMed, Latin American and Caribbean Literature in Health Sciences, and Scientific Electronic Library Online. We selected articles that were published in Portuguese, English, and Spanish over the last 10 years. Data analysis was performed using a validated data collection instrument.

Results: Among the 289 articles identified in the search, 276 were excluded because they did not address the leading research question, their full texts were not available on the Internet, or they were duplicate publications. Therefore, for the analysis, we selected 13 articles that we classified as randomized clinical studies $(46.15 \%$; $n=6)$, cohort studies $(30.76 \% ; n=4)$, crosssectional studies $(7.69 \% ; n=1)$, case studies $(7.69 \% ; n=1)$, and review articles $(7.69 \% ; n=1)$. Joint intervention (combined in-person and telecoaching sessions) constituted the majority of session types. The use of technical coaching was superior in reducing anthropometric measurements and increasing the levels of motivation and personal satisfaction compared with formal health education alone.

Conclusion: Coaching is an efficient, cost-effective method for combining formal education and treatment of health in the weight-loss process. Additional randomized studies are needed to demonstrate its effectiveness with respect to chronic disease indicators.

Keywords: coaching, weight loss, quality of life, health promotion, neurolinguistic programming

\section{Introduction}

Medical and nutritional assistance for overweight patients is a complex and dynamic issue. Studies have shown that in obese patients, the prevalence of type II diabetes is between $50.9 \%$ and $98.7 \%$, and the prevalence of hypertension exceeds $80 \%$ in European countries. ${ }^{1}$ The incidence of overweight and obesity has increased in diverse and distinct populations and is an important topic worldwide. ${ }^{2}$ Treatment for obesity based on medication alone is poorly effective. The average weight loss observed with the use of different antiobesity medications (orlistat, diethylpropion, sibutramine, mazindol, and topiramate) is between 2.9 and $4.2 \mathrm{~kg}$ or $\sim 6.5 \%$ of a person's weight per year, indicating difficulty in achieving the desired weight. ${ }^{3}$

These observations emphasize the necessity of lifestyle change along with medicine as the main way to control obesity. Physical education and a diet rich in vegetables with reduced levels of sugar and fat appear to be universally recommended. However, 
developing healthy habits is challenging and requires changes in attitudes and motivational skills.

In 2014, Hammarström et al interviewed overweight and obese women participating in a dietary intervention and found that the primary barriers to adhering to the measures were related to internal struggles, such as challenges encountered in modifying eating habits, low levels of self-control, and insecurity. Additionally, they found that having clear objectives and receiving support from family and project members were facilitators. ${ }^{4}$

Motivating and helping people to change negative health behavior is a considerable challenge for health care professionals. Health coaching (HC) is a consultation model to address this challenge. ${ }^{5}$ Coaching is the process of leading individuals from a current state toward their desired state. In this process, the coach or the professional, who applies the method, accompanies the client. The client defines the objectives and actions for achieving his or her goals. The role of the coach is to challenge the client by using different tools. Questioning and monitoring the client's actions can improve patient self-confidence and incite the patient to change. To become a health coach, previous health training is not necessary; however, training and, in some cases, international certification in professional coaching are required. Attendance can be in person, via telephone, via the Internet, or in a group session.

Ammentrop et al noted a tendency for improvement in health status with life coaching, with a special focus on diabetic adolescents. In their study, a significant improvement in the rate of $\mathrm{HbA1c}$ was observed; this finding was especially relevant because the study addressed a group of patients in whom treatment tended to be unsuccessful in the short-term. ${ }^{6}$

Coaching is intended to increase patient awareness and responsibility by transforming the professional-patient relationship. Evidence suggests that patient involvement in the decision process with self-determination, self-responsibility, and propriety has positive effects on motivation, satisfaction, adherence, and health results. ${ }^{7,8}$ Therefore, the aim of this study was to contribute to the scientific literature by determining how coaching can help the process of weight loss and improve the state of health in the general population.

\section{Methodology}

An integrative review (IR) of the literature was performed to summarize previous empirical and theoretical literature and provide an extensive understanding of coaching in weight loss. This research method targeted the analysis and synthesis of knowledge already built on previous research concerning a specific theme, allowing for new knowledge generation. $^{5}$

The IR was based on the proposal by Mendes et al, ${ }^{9}$ which describes the following six stages: theme identification and selection of the research question, establishment of inclusion and exclusion criteria, definition of information to be extracted, evaluation of the studies included in the IR, interpretation of the results, and presentation of the review/ synthesis of knowledge. The objectives of this IR were to relate "coaching" tools to weight loss and health and answer the following question: How can coaching assist in the process of weight loss and improve the state of health of the general population? The search for indexed publications was conducted in February 2015 using the following databases: PubMed, Scientific Electronic Library Online, and Latin American and Caribbean Literature in Health Sciences. The descriptors used were "coaching" and the keywords "weight loss," "quality of life," "health promotion," and "neurolinguistic programming;" "AND" was used as a Boolean operator between the descriptor and the keywords.

The inclusion criteria were as follows: The publication was an original article, case study, or review article that addressed the research question; it was published between 2000 and 2015 in Portuguese, English, or Spanish; and the complete text was available for analysis. We excluded duplicate publications. The search was conducted in an orderly manner using PubMed, Scientific Electronic Library Online, and Latin American and Caribbean Literature in Health Sciences.

To organize the information as well as tabulate and analyze the data, a data collection instrument validated by Ursi and Gavão in 2006 was used (Figure S1). ${ }^{10}$ The present study followed ethical principles, respecting the authorship and data presented in the articles.

We identified 289 articles about coaching from the literature search. Among them, 287 articles were identified from the PubMed database, of which 274 were excluded because they did not address the leading research question or their full texts were not available on the Internet. Two articles were identified in the Latin American and Caribbean Literature in Health Sciences database: one that had already been selected in the PubMed database, and one that did not meet the inclusion/exclusion criteria. No articles were found in the Scientific Electronic Library Online database. Thus, the review was conducted with the 13 articles that met the established criteria. 


\section{Results and discussion}

The majority of studies were published between 2013 and 2014. Most of the studies were from the US ( $n=8)$, with the remainder from South Africa, Turkey, Australia, Finland, and Cuba. We classified the studies as follows: randomized clinical trial $(46.15 \% ; \mathrm{n}=6)$, cohort $(30.76 \%$; $\mathrm{n}=4)$, cross-sectional $(7.69 \% ; n=1)$, case $(7.69 \% ; n=1)$, and review $(7.69 \% ; n=1)$ (Table 1). Interventions consisted of two types: in-person and mixed (in-person sessions with associated telecoaching). The durations of the sessions studied ranged from 5 to 90 minutes, and the session frequency was weekly or every 3 months (Table 2).

\section{Barriers to weight loss}

In 2014, Venditti et al published a study that analyzed the barriers experienced by participants and the most frequently used coaching tools in the diabetes prevention program. The intervention protocol consisted of in-person sessions. In the initial eight sessions, the participants learned self-regulation skills for setting goals. In sessions 9 to 16 , the participants were coached in responding to social and psychological stimuli and stress. During the postcore phase (maintenance), after 6 months in this phase, the participants were contacted in person, by telephone, or by email at least bimonthly. During the first 16 sessions, the most frequent barriers associated with weight loss were problems with self-monitoring (58\%), social events (58\%), vacations and holidays (54\%), little physical activity (48\%), and internal cues (thought/humor) (44\%). More than $75 \%$ of the participants reported encountering a barrier during the intervention and maintenance phases. Barriers to physical activity included vacation (51\%), time management (50\%), internal signs (thought/humor) (30\%), illness (29\%), and motivation (26\%). A behavior change intervention based on intended outcomes was more efficient than medication treatment or placebo in delaying the onset of diabetes for more than 3.2 years. It can also be concluded that the coaching approach can benefit participant assessment of diet self-monitoring skills. ${ }^{11}$

\section{Positive and negative results in randomized clinical trials}

Leahey and Wing conducted a randomized clinical trial in 2013 and obtained positive results regarding the viability, acceptability, and preliminary efficiency of three types of health coaches for the treatment of obesity. The individuals were randomly assigned to one of three types of coaches: professional coach $(n=16)$; peer coach $(n=16)$ (ie, a colleague with the same objectives), and mentor, namely, someone who has already been successful in achieving the same objective $(n=12)$. The intervention was the same for the three groups, as shown in Table 1. During the 12 weeks, the participants emailed the following data to their professional coach, peer coach, or mentor: weight, calories consumed, and information on physical activity. Depending on the results, they also received feedback. The individuals who received professional and peer coaches had weight losses of 9.6 \pm 8.1 and $9.1 \pm 5.0 \mathrm{~kg}$, respectively. In contrast, the mentor group exhibited weight loss in relation to the initial weight of $5.7 \pm 5.6 \mathrm{~kg}$. The participants expressed satisfaction with the weight-loss program. Therefore, the professional coach, peer coach, and mentor approaches were all viable and acceptable for promoting weight loss. ${ }^{12}$

In 2013, Shahnazari et al also obtained positive results regarding coaching in a randomized clinical trial. The objective was to determine whether wellness coaching could be an efficient method for promoting healthy eating habits and weight control. The participants were randomly separated into the control or intervention group. Both groups received an initial 60-minute session on individualized nutritional education. The remaining sessions were 15 minutes long. Participants in the intervention group received wellness coaching weekly in an in-person session or telephone visit during the second month of the study and once a month for the subsequent four months. There were 3.75 hours of educational contact for the intervention group and 1 hour for the control group by the same wellness coach. An average weight loss of $5 \%$ was observed in the intervention group after 6 months $(92.8 \pm 4.1 \mathrm{~kg}$ vs $88.2 \pm 3.4 \mathrm{~kg} ; P=0.006)$. In the control group, no alteration in body weight was observed $(88.7 \pm 5.4 \mathrm{~kg}$ vs $87.4 \pm 4.6 \mathrm{~kg}$; $P=0.33$ ). In the intervention group, $73 \%$ of the participants lost weight, $15 \%$ gained weight, and $12 \%$ did not exhibit weight changes after 6 months. In the control group, 26\% of the participants lost weight, $64 \%$ gained weight, and $10 \%$ had no weight change. The study showed that the participants subjected to wellness coaching lost a significant amount of body weight and consequently decreased their body mass index (BMI), likely due to the reduction of energy consumption. The results indicated that wellness coaching can be an efficient approach for promoting the reduction of energy consumption and weight loss in North American veterans. ${ }^{13}$

In 2008, Tucker et al conducted a randomized clinical trial to evaluate the efficiency of two weight-loss interventions: coaching via telephone and receiving a weight-loss supplement. They concluded the trial with positive results. The investigators, coaches, and participants were blinded to 
Table I The included studies

\begin{tabular}{|c|c|}
\hline Author/year & Outline - population and sample \\
\hline $\begin{array}{l}\text { Adams et al } \\
(2013)^{19}\end{array}$ & $\begin{array}{l}\text { Cross-sectional study of } 446 \text { patients, } \\
83 \% \text { of whom were women, with an } \\
\text { average age of } 56 \text { years }\end{array}$ \\
\hline $\begin{array}{l}\text { Cinar and } \\
\text { Schou }(2014)^{16}\end{array}$ & $\begin{array}{l}\text { Randomized clinical study with } 186 \\
\text { participants with type II diabetes } \\
\text { mellitus between } 30 \text { and } 65 \text { years } \\
\text { of age }\end{array}$ \\
\hline
\end{tabular}

Mettler et al $(2014)^{20}$

O'Hara et al $(2013)^{21}$

Patja et al $(2012)^{17}$

Wolever et al $(201 \mathrm{I})^{22}$

Bonal Ruiz et al $(2012)^{23}$

Venditti et al $(2014)^{\prime \prime}$
Prospective cohort study of 177 patients/members of the well-being center with an average BMI of $34.4 \mathrm{~kg} / \mathrm{m}^{2}, 92 \%$ women, and an average age of 42.9 years Cohort study of 277 patients of Australia's GHS; $79.1 \%$ of the participants were women, and the average age was 48.4 years

Randomized clinical study of I,22I patients $>45$ years of age with type II diabetes mellitus, coronary disease, and congestive heart failure

Organizational case study with six coaches and 360 clients

Narrative review article

Cohort study with 3,234 participants from 27 centers enrolled in the DPP. The average age was 50.6 years and $68 \%$ of participants were female

Intervention

Wellness coaching sessions conducted

via telephone that focused on lifestyle changes

In the intervention group, that is, the group receiving health coaching, participants had sessions with the coach in person and via telephone. The participants in the control group (formal education) received orientation from a dentist followed by in-person and telephone sessions focused on education and delivered by a nutritionist and a nurse specialist in diabetes.

Sessions with wellness coaches, the first from 60 to 90 minutes and then 30-60 minutes weekly for 3 months for a total of 12 in-person sessions

Coaching sessions were conducted via telephone for 6 months.

Anthropometric data, consumption of fruits and vegetables, and physical activity were evaluated. Sessions were conducted also at the end of 12 months of the initial date. The anthropometric measurements were provided by the participants themselves (they received instruction regarding the measurements).

Health coaching sessions were performed by trained and certified nurses or nurses in public health. Patients in the intervention group were contacted via telephone once a month, ten to eleven times. The coaching calls lasted $>60$ minutes.

An independent researcher who was not involved in the coaching process revised three programs in integrative health coaching at the Duke School of Integrative Medicine

Literature review regarding the concept of coaching in health, the limitations between traditional health education and the advantages of coaching, evidence of effectiveness in primary health, coaching techniques, and the importance of intersectoriality Sixteen sessions in which the participants learned coaching skills to achieve goals. The postcore period involved continued evaluation of the ability to resolve problems $\sim 6$ months from the beginning of the study
Main findings

Wellness coaching programs via telephone can help patients achieve their health goals

Health coaching significantly improved the management of oral health and glucose control compared with formal health education

Coaching was effective in enhancing motivation for behavioral change action. Additional randomized studies of the potential benefits of wellness coaching are recommended.

Preliminary evidence indicates that the GHS has the potential to substantially improve the profile of patients with chronic diseases and facilitate the maintenance of weight loss at 6 months following the program's end

Individualized health coaching via telephone was not effective in achieving the majority of clinical objectives measured. The authors stated that the interventions should have been more intensively applied in the selected groups.

When the relationship between client and professional allows compromise, the client can discover strategies for change that can be adapted to particular situations. The authors recommend that coaching training that is recognized by the International Coaching Federation be used. Health coaching is a promising approach. It is necessary to overcome doctor-centered thinking and consider intersectoriality and the local political will.

Problem-solving and evaluations of selfmonitoring competencies were the most common approaches used by the coaches. Minimum resources, such as nutritional education, email, and telephone calls, given to professionally trained coaches to facilitate these approaches for adherence to the treatment appeared justified 


\begin{tabular}{lll}
\hline Author/year & Outline - population and sample & Intervention \\
\hline Temmingh et al & Cohort study over I2 months of 76I & Telecoaching sessions with health risk \\
$(2013)^{18}$ & psychiatric outpatients of the Lily & $\begin{array}{l}\text { and lifestyle habit evaluation were } \\
\text { conducted that provided exercise and }\end{array}$ \\
& Wellness Plus Program; patients & meal plans. The telecoaches were \\
women, and 213 were men & nutritionists and physical educators with \\
& & experience in coaching techniques and \\
& were registered with the Health \\
& Professions Council of South Africa
\end{tabular}

Leahey and Randomized clinical trial with Wing $(2013)^{12} \quad 44$ patients; patients were men and women with BMls of between 30 and $40 \mathrm{~kg} / \mathrm{m}^{2}$ and an age range of 40-60 years

Shahnazari et al $(2013)^{13}$

$\mathrm{n}=73$ men and eleven women.
Average age was 55 years in the
control group and 54 years in the
intervention group

Gabriele et al $(2011)^{15}$

Randomized study (single-blinded) of 104 employees of the University of North Carolina. Participants were 30-60 years of age with a BMI of $25-40 \mathrm{~kg} / \mathrm{m}^{2} ; \mathrm{n}=87$ women
Tucker et al $(2008)^{14}$
Randomized study with

128 participants; age range, 25-60 years; average, $43 \pm 9.64$ men and 64 women; BMI, $25-35 \mathrm{~kg} / \mathrm{m}^{2}$
The participants underwent a weight-loss program of 6 months and were randomly assigned to one of the three coach conditions: professional coach, peer coach, and mentor. The intervention was the same for the three groups and included in-person meetings and feedback by email Control group: $n=41$. Intervention group: $n=43$. The coaching sessions focused on nutrition and healthy eating habits and the use of motivational interviewing techniques to help veterans move through the stages of behavioral change

Groups: minimal support; weekly lesson by email, with standardized order and weekly feedback. Directive support; weekly classes standardized by email. The e-coach evaluated the self-reported weight and formulated the goals and tasks. Nondirective support; the participants decided what objectives and strategies to follow. The e-coach's weekly support was to incentivize the identification of goals and overcoming of obstacles

Randomization groups: coaching

+ placebo, coaching + active supplement, active supplement + noncoaching. Coaching intervention via telephone through the coach trained in weight loss. Supplement intervention through the ingestion of capsules containing micronutrients and herbal medicine or placebo
Main findings

Considering that the magnitude of weight loss was moderate and decreased significantly over time, with $46 \%$ of the patients losing more than $5 \%$ of their initial weight, patients with severe mental illness at a young age with a diagnosis of mood disorder or chronic diseases may require more intensive interventions, such as in-person sessions

The patients reported that they were satisfied with the weight-loss program. Thus, professional coach, peer coach, and mentor are all viable and acceptable approaches for enhancing weight loss. The results suggested that professional coaches and peer coaches can be superior to mentors

The intervention group that received wellness coaching exhibited weight loss, a reduction in calorie consumption, and more motivation during treatment compared with the control group

Directive support might have been more effective than the intervention of weight loss due to the simplification of objectives for the participants via email. Thus, this study provides evidence that Internet programs can be an effective means of helping individuals lose weight

The adults who took the supplement and received coaching lost double the weight and body fat compared with those who took the supplement but did not receive coaching or those who received coaching but took the placebo. Coaching via telephone plus supplement for weight loss seemed to be effective interventions for losing weight, especially when combined

Abbreviations: BMI, body mass index; DPP, diabetes prevention program; GHS, Get Healthy Information and Coaching Service.

the study. Some participants received capsules that contained the active supplement (a mixture of phytotherapeutic agents and micronutrients) to lose weight, and others received the same supplement in the inactive form, that is, as placebo. The participants were advised to consume four capsules per day, two in the morning and two at night, with their meals and to document their adherence. The supplement composition was developed primarily to improve glucose control by increasing metabolism, improving the sense of well-being, and reducing appetite, thus leading to weight loss. The coaching intervention predominantly consisted of a telephone conversation between the participant and a coach trained in weight loss. In each coaching session, the participants reported their successes and failures. The supplement group consisted of 64 participants (50\% women), and 64 individuals were assigned to the placebo group ( $50 \%$ women). Fifty percent of the individuals who were in the supplement group also received coaching to lose weight; the remaining 50\% did not receive coaching. The results showed that the individuals who received both active supplementation and weight-loss 
Table 2 Session duration, interval of application, intervention time, intervention type, and country of the included studies

\begin{tabular}{|c|c|c|c|c|c|}
\hline Study & $\begin{array}{l}\text { Coaching } \\
\text { session time }\end{array}$ & $\begin{array}{l}\text { Coaching interval } \\
\text { of application }\end{array}$ & $\begin{array}{l}\text { Intervention } \\
\text { time }\end{array}$ & $\begin{array}{l}\text { Intervention } \\
\text { type }\end{array}$ & Country \\
\hline Venditti et al (2014)'। & Not reported & $\begin{array}{l}\text { I-I } 6 \text { weeks: IX/week; } \\
\text { after } 6 \text { months: bimonthly }\end{array}$ & 3.2 years & $\begin{array}{l}\text { In-person session, } \\
\text { telephone, or email }\end{array}$ & USA \\
\hline Temmingh et al $(2013)^{18}$ & $5-30$ minutes & $\begin{array}{l}\text { First } 3 \text { months: } I \times / \text { week, after: } \\
I \times / \text { month }\end{array}$ & 12 months & Telephone & $\begin{array}{l}\text { South } \\
\text { Africa }\end{array}$ \\
\hline Leahey and Wing $(2013)^{12}$ & $\begin{array}{l}\text { I hour to I hour } 30 \\
\text { minutes }\end{array}$ & $\begin{array}{l}\text { First } 6 \text { weeks: } \mathrm{I} \times / \text { week; } 7 \text { th to } \\
\text { I2th weeks: every } 2 \text { weeks; } \\
\text { I3th week onward: } I \times / \text { month }\end{array}$ & 6 months & $\begin{array}{l}\text { In-person session } \\
\text { and email }\end{array}$ & USA \\
\hline Shahnazari et al $(2013)^{13}$ & 15-60 minutes & $\begin{array}{l}\text { Ist month: IX week; 2nd month } \\
\text { onward: I } \times / \text { month }\end{array}$ & 6 months & $\begin{array}{l}\text { In-person session } \\
\text { and telephone }\end{array}$ & USA \\
\hline Gabriele et al $(201 \mathrm{I})^{15}$ & Not reported & $\mathrm{I} \times /$ week & 12 weeks & Email & USA \\
\hline Tucker et al (2008) ${ }^{14}$ & 30-90 minutes & $\mathrm{I} \times /$ week & 17 weeks & Telephone & USA \\
\hline Adams et al $(2013)^{19}$ & $10-30$ minutes & Up to four per year & 6 months & Telephone & USA \\
\hline Cinar and Schou $(2014)^{16}$ & $\begin{array}{l}\text { 8-10 minutes from the } \\
\text { second session onward }\end{array}$ & One every $10-15$ days & 10 months & $\begin{array}{l}\text { In-person session } \\
\text { and telephone }\end{array}$ & $\begin{array}{l}\text { Turkey and } \\
\text { Denmark }\end{array}$ \\
\hline Mettler et al $(2014)^{20}$ & 30-90 minutes & $\mathrm{I} \times /$ week & 12 weeks & In-person session & USA \\
\hline O’Hara et al $(2013)^{21}$ & Not reported & Not reported & 6 months & Telephone & Australia \\
\hline Patja et al $(2012)^{17}$ & More than 60 minutes & $\mathrm{I} \times /$ month & I0-II months & Telephone & Finland \\
\hline Wolever et al $(20 \mathrm{II})^{22}$ & $\begin{array}{l}60-120 \text { minutes for group } \\
\text { sessions and } 20-30 \text { minutes } \\
\text { for individual sessions }\end{array}$ & I $\times /$ week to biweekly & 6-10 months & $\begin{array}{l}\text { Telephone or } \\
\text { in-person session }\end{array}$ & USA \\
\hline
\end{tabular}

coaching via telephone had a greater loss of body weight and fat compared with each of the other groups. Both treatments contributed to weight and fat loss either alone or in combination. Both of the evaluated weight-loss treatments, that is, use of a weight-loss supplement and coaching via telephone, appeared to be efficient interventions. When used separately, their benefits were significant; however, when used in combination, the effects on weight loss were superior. ${ }^{14}$

In a single-blinded, randomized clinical trial in 2011, Gabriele et al examined how different types of e-coaching influenced weight loss, behavioral change, and intervention involvement. The participants were divided into three groups: minimal support $(n=34)$, nondirective support $(n=35)$, and directive support $(n=35)$. All of the participants had in-person evaluations (initial and final) and underwent treatment online between 4 and 8 weeks. All of the participants, including the minimal support group, participated in a weight-loss program conducted online, with information and feedback delivered by email. In the minimal support group, the participants received only a weekly lesson by email, according to a standardized protocol, and weekly feedback. The support was individualized, and the feedback contained only charts. In the directive support group, the participants received homogenous weekly lessons by email, and in the return email, the e-coach evaluated the self-reported weight to determine whether the participant was losing weight. The objectives and goals of the treatment were provided to the participants, and the e-coach assumed responsibility of the goals. In the nondirective support group, the participants were responsible for the tasks and goal decisions. The nondirective support of the e-coach was structured to assist the participants' choices, motivating them to identify their objectives. The participants chose their own objectives and strategies. Weight loss as a result of the intervention was significant; men lost more weight in the nondirective support group $(M=-9.20 \mathrm{~kg})$ than in other groups. Weight loss among women was higher in the directive support group ( $M=-4.82 \mathrm{~kg}$ ) than in the other two groups. Regarding physical activity, there was a significant difference between women in the directive support group and those in the minimal support group $(P=0.01)$. The authors concluded that although weight loss occurred in the nondirective support and minimal support groups, the approach of directive support by e-coaching through the Internet was more beneficial for weight loss, reduction of waist circumference, and improvement of physical activity in women during the first 12 weeks of a weight-loss program. In this case, the typical coaching intervention, nondirective support, produced an inferior weight-loss result. ${ }^{15}$

In 2014, Cinar and Schou evaluated whether a HC approach could improve glucose control and oral health compared with formal health education among patients with type II diabetes mellitus and obtained positive results. The patients were randomized to receive $\mathrm{HC}$ and had in-person and telephone sessions. The main method involved assisting 
each patient in developing an objective and action plan, which was focused on improving the patient's lifestyle through selfefficacy, self-esteem, and taking responsibility for his or her own health. The participants in the formal education group (control) received instruction from a dentist and six sessions that focused on education by a dietitian and a nurse specialist in diabetes. There was a significant reduction in $\mathrm{HbA} 1 \mathrm{c}(16 \%$ vs $5 \%, P<0.01)$ in the highest risk group $(\mathrm{HbA} 1 \mathrm{c}>8 \%)$ and stress reduction (HC group 39\% vs formal education group $2 \%, P<0.01)$ in addition to significant improvement in oral health markers. The coach who carried out the intervention in the $\mathrm{HC}$ group possessed previous knowledge of dental health and was the main author of the study. ${ }^{16}$

Noncommunicable chronic diseases are closely related to bad eating habits and a sedentary lifestyle. In 2012, Patja et al conducted the TERVA study, which was a randomized trial of patients with type II diabetes mellitus, heart failure, and coronary artery disease. In the control group, patients were submitted to routine operations by specialist nurses, and in the intervention group, patients had monthly calls for a 1-year period with sessions aimed at informing, involving, and empowering patients through coaching techniques. The coaches were nurses certified in public health and trained for 4 months. Specific outcomes were established, such as blood pressure $\leq 140 / 85 \mathrm{mmHg}$ and $\mathrm{HbA} 1 \mathrm{c} \leq 7 \%$. There was a statistically significant increase in the number of patients (48\%) who achieved a diastolic pressure in the target range (85 $\mathrm{mmHg}$ ) in the intervention group compared with the control group (37\%), with a number needed to treat of ten (confidence interval =5-66). There were no significant differences regarding cholesterol, waist circumference, $\mathrm{HbAlc}$, or maintenance or improvement of heart failure class between the groups; however, the targets of systolic blood pressure and waist circumference were achieved more frequently in the intervention group. Interestingly, the author reported that specialist nurses in the control group may have felt challenged in their professional role and put more effort into their work, which could explain the close results between the groups. ${ }^{17}$

\section{Positive and negative results in observational studies}

To evaluate the intervention of coaching via telephone that was aimed at reducing weight and improving the well-being of psychiatric outpatients, Temmingh et al conducted a 12-month cohort study in 2013. The first telecoaching session lasted 20 to 30 minutes and included an extensive questionnaire evaluating health and life habit risks. At the end of the first session, an exercise and meal plan was compiled by the telecoach, which was personalized according to the objectives and needs of each participant. The participants were allowed to establish their own goals according to the level and degree of exercise in which they wanted to participate, guided by realistic and desired results. Telecoaching follow-up sessions lasted 5 to 10 minutes and were conducted weekly during the first 3 months and monthly from 4 to 12 months. The sessions were administered by a nutritionist and biokineticist telecoaches who had experience in coaching techniques and were registered with the Health Professions Council of South Africa. The general compliance was adequate during the first 3 months of the study, with grades of adherence to the meal plan that varied from good to excellent in $81.8 \%$ of the participants at 4 weeks, $81.4 \%$ at 8 weeks, and $86.3 \%$ at 12 weeks. The adherence classifications to physical activity were lower but nonetheless within the range of acceptable to good. At the end of the study, the average weight loss of the group was $-4.8 \%$ (95\% confidence interval 5.67/-3.82), and $46 \%$ of the participants experienced a loss of $\geq 5 \%$ of their initial weight. The average waist circumference reduction was $-6.8 \mathrm{~cm}(95 \%$ confidence interval $-8.49 /-5.19)$. Coaching via telephone can result in significant weight reductions and general health improvement in a cohort of patients with serious mental illnesses who live in the community and receive pharmacological treatment. ${ }^{18}$

Another study with sessions conducted via telephone evaluated a sample of patients with a desire to improve their lifestyle. The levels of motivation and changes were evaluated using a questionnaire. The Patient Activation Measure 6 maps four levels of patient activation: level 1: might not believe that the role of the patient is important; level 2: lacks self-confidence and the knowledge to initiate actions; level 3: begins to act; and level 4: has difficulty in maintaining the behaviors for a long period of time. The majority (60\%) of the patients were satisfied or extremely satisfied with the process. Those who participated in more than one session were more satisfied with the program $(P<0.001)$ and were more likely to recommend wellness coaching $(P=0.007)$. Furthermore, those who participated more frequently reported that coaching helped them become accustomed to eating healthier $(68 \%$ vs $54 \%, P=0.04)$, helped them to increase their physical activity $(71 \%$ vs $45 \%, P<0.001)$, improved their health $(79 \%$ vs $61 \%, P=0.005)$ and quality of life $(83 \%$ vs $61 \%, P<0.001)$, and reduced their risk of disease $(73 \%$ vs $51 \%, P=0.01)$. The Patient Activation Measure 6 score was significantly higher among patients who reported more satisfaction with the program and among those who believed that the process helped to achieve their weight objectives. It was concluded 
that the patients who completed a greater number of sessions and who were initially more motivated had a higher perception of success and satisfaction. ${ }^{19}$

The number of professionals using wellness coaching is growing, as is the number of health and well-being programs. In 2014, Mettler et al conducted a prospective study to evaluate the efficiency of wellness coaching and the reasons that people seek assistance via this modality. The evaluation was conducted using questionnaires at the beginning of the process and at the end at 3 months. They found that $100 \%$ of participants lost or maintained their weight; $93 \%$ managed or prevented diseases; and $81 \%$ improved their wellbeing. After 3 months, the patients presented a significantly greater awareness of the importance of health, showed more self-confidence regarding their behaviors related to health (satisfaction with their lives, level of energy, healthy weight, level of physical activity, healthy eating, mental/emotional skills, and personal health care), and had reduced BMI (the initial average of $34.2 \mathrm{~kg} / \mathrm{m}^{2}$ was reduced to $33.3 \mathrm{~kg} / \mathrm{m}^{2}$ ). Furthermore, at the beginning of the process, $65.9 \%$ were in the action and maintenance motivational stage, whereas $93.6 \%$ of the participants progressed to this stage after 3 months. ${ }^{20}$

The Australian program Get Healthy Information and Coaching Service was introduced by the government and made available to the general population. It is based on the provision of information and coaching processes via telephone and is aimed at assisting adults and implementing lifestyle changes. To evaluate the program's effectiveness regarding not only anthropometrical and behavioral changes but also the maintenance of these changes, O'Hara et al conducted a cohort study in 2013 in which they assessed patients initially, at the end of the program at 6 months, and at 12 months. Significant improvements were found between the initial and 12-month time points in the adjusted average weight $(-2.9 \mathrm{~kg})$, abdominal circumference $(-5.4 \mathrm{~cm})$, and BMI $\left(-1.1 \mathrm{~kg} / \mathrm{m}^{2}\right)$. Additionally, increases in daily fruit and vegetable consumption and the number of physical activity sessions per week $(+1.8)$ were observed. No significant difference in weight, abdominal circumference, BMI, or fruit consumption was observed between the 6-and 12-month time points, indicating the results of the program were maintained over time. There was a significant reduction in vegetable consumption at the end of 12 months, and there was a significant increase in the number of physical activity sessions per week of 1.2 after 6 months following the end of the coaching program. Additionally, $49 \%$ of the participants maintained or continued to lose weight after 6 months, and $63 \%$ maintained or further reduced their abdominal circumference. ${ }^{21}$

\section{Coaching tools used in weight loss}

According to the International Coaching Federation, coaching is based on human development theories, humanistic psychology, positive psychology, motivational interviewing, organizational psychology, leadership development, and solution-focused therapy. ${ }^{22}$ Furthermore, it uses techniques of neurolinguistic programming and self-efficacy. ${ }^{16}$

In an organizational case study, Wolever et al highlighted the differences between coaching and psychotherapy. In coaching, the person has an objective and wants to achieve it, whereas in psychotherapy, the person has a problem to be resolved. ${ }^{22}$ The coaching approach differs from that used by a specialist in the health area. ${ }^{22,23}$ The specialist treats the patient, provides the knowledge, skills and expertise, strives to have all the answers, focuses on the problem, and offers advice; the coach encourages patients to help themselves, builds motivation, confidence and commitment, relies on patient awareness, and strives to help patients find their own answers, focusing on what is working well. ${ }^{23,24}$ This tool may not be beneficial for everyone because it is based on true feedback, open communication, and the belief that the client possesses everything he or she needs to achieve his or her objectives. Some clients who are more susceptible may not tolerate the challenging attitude of coaching. ${ }^{22}$

Using an approach focused on strengths, HC promotes respect and confidence within individuals and groups. It allows individuals to identify their own strengths and provides them with tools to overcome difficulties and apply communication strategies. Furthermore, HC inspires hope, offers solutions, increases competence, and strengthens positive changes. ${ }^{20}$

Among the most discussed tools in this research field is motivational interviewing, which a time-limited interviewing method that is characterized by an empathetic style. It is centered on the client, focuses on behavioral change, provides feedback on the consequences of a behavior relative to health, and shows the discrepancies between the desired objective and the current behavior. ${ }^{13,15,17,18,23}$ In a motivational interview, the patient can be categorized according to his or her level of motivation: precontemplation (I do not want to do it or I cannot do it); contemplation (I want and can do it, but I will leave it for later); preparation (I am going to do it); action (I am doing it, but not regularly); and maintenance (I continue doing it). ${ }^{13,23}$

Additionally, to approach the difficulties encountered in the process, behavioral problem-solving has been proposed, which consists of the following five steps: 1) positive orientation, 2) definition of behavioral problem/chains, 3) generation of alternatives, 4) establishment of attainable goals, and 5) implementation of trial and error. ${ }^{11,12,18}$ 
Aimed at increasing patient self-efficacy, the self-monitoring technique has been discussed extensively. ${ }^{11,12,14,15,17,18,23}$ This technique enhances the patient's attention and responsibility for his or her own actions, reducing his or her dependency on the professional. Self-monitoring consists of objectively recording frequent behaviors. To lose weight, the counting of calories, fats, and fibers and the recording of the duration and intensity of physical activity can be used. ${ }^{15}$

Another common tool in coaching studies is the establishment of objectives. ${ }^{11,12,16-18,22,23}$ In coaching, the objective tends to be specified using the SMART technique, that is, the goal must be specific, measurable, action-oriented, and realistic, and it must be able to be completed within a specific period of time. ${ }^{22,23}$ Using this tool, the future visualization of the results can be performed and a sense of purpose of the objective can be sought by presenting the participant with questions, such as "What will you be able to do when you accomplish it?" and "What will be different in your life?"22 In the TERVA study, the importance of the questioning technique was addressed, including the use of open questions, that is, questions that provoke answers with more content rather than simple responses, such as "yes" or "no."17 After establishing the objective, the action planning tool is defined, in which the patient questions him- or herself about what he/ she wants to accomplish, what he/she is going to do, how and when he/she will do it, who he/she can rely on, what resources he/she possesses, what resources he/she needs, and the time frame in which the objective should be accomplished. In this action plan, the patient is the protagonist in all of the tasks. ${ }^{16,17}$

\section{Conclusion}

This IR showed that coaching can be a useful method in the treatment of overweight individuals and has a high level of applicability via in-person, telephone, or Internet sessions. In formal health education, we learn that when ill patients seek medical treatment from a professional, they wish to improve and thus follow the provided prescription. In weight loss, this concept does not apply because there are discrepancies between what the patients desire and their behavior. Thus, it becomes difficult for the professional and the patient to achieve the expected results. Coaching tools appear to address these discrepancies; that is, they help to align the objective with the necessary actions. Coaching has been shown to be efficient in allowing the patient to experience and achieve more motivation, more satisfaction, and a better sense of well-being using validated scales. Furthermore, in the majority of randomized and cohort studies, there were significant reductions in weight and weight-associated measurements. In the reviewed literature, the interventions were always conducted after formal education by health care professionals. In relation to objective results, such as control indicators of chronic diseases, randomized studies to assess the effectiveness of coaching are warranted. In conclusion, in the weight-loss process, coaching is an efficient and cost-effective method that can be used in association with education and formal treatment in health.

\section{Disclosure}

The authors report no conflicts of interest in this work.

\section{References}

1. Colosia AD, Palencia R, Khan S. Prevalence of hypertension and obesity in patients with type 2 diabetes mellitus in observational studies: a systematic literature review. Diabetes Metab Syndr Obes. 2013;6:327-338.

2. Williams EP, Mesidor M, Winters K, Dubbert PM, Wyatt SB. Overweight and obesity: prevalence, consequences, and causes of a growing public health problem. Curr Obes Rep. 2015;4(3):363-370.

3. Guaraldi F, Pagotto U, Pasqual R. Predictors of weight loss and maintenance in patients treated with antiobesity drugs. Diabetes Metab Syndr Obes. 2011;4:229-243.

4. Hammarström A, Wiklund AF, Lindahl B, Larsson C, Ahlgren C. Experiences of barriers and facilitators to weight-loss in a diet intervention a qualitative study of women in Northern Sweden. BMC Women's Health. 2014;14(1):59.

5. Jones P, McDowell A, Viney R. Coaching for health: holding the curtains so patients can change. Br J Gen Pract. 2013;63(611):318-319.

6. Ammentorp J, Uhrenfeldt L, Angel F, Ehrensvärd M, Carlsen EB, Kofoed PE. Can life coaching improve health outcomes?-A systematic review of intervention studies. BMC Health Serv Res. 2013;13(1):428.

7. Neuner-Jehle S, Schmid M, Grüninger U. The "Health Coaching" programme: a new patient-centred and visually supported approach for health behaviour change in primary care. BMC Fam Pract. 2013;14(1):1.

8. Botelho LL, Cunha CC, Macedo M. O método da revisão integrativa nos estudos organizacionais [The integrative review method in organizational studies]. Gestão e Soc. 2011;5(11):121-136. Portuguese.

9. Mendes KD, Silveira RC, Galvão CM. Revisão integrativa: método de pesquisa para a incorporação de evidências na saúde e na enfermagem [Integrative review: a research method to incorporate evidence in health and nursing]. Texto and Contexto Enfermagem. 2008;17(4):758-764. Portuguese.

10. Ursi ES, Gavão CM. Prevenção de lesões de pele no perioperatório: revisão integrativa da literatura [Prevention of skin lesions in the perioperative: integrative literature review]. Revista Latino-Americana de Enfermagem. 2006;14(1):124-131. Portuguese.

11. Venditti EM, Wylie-Rosett J, Delahanty LM, Mele L, Hoskin MA, Edelstein SL; Diabetes Prevention Program Research Group. Short and long-term lifestyle coaching approaches used to address diverse participant barriers to weight loss and physical activity adherence. Int J Behav Nutr Phys Act. 2014;11:16.

12. Leahey TM, Wing RR. A randomized controlled pilot study testing three types of health coaches for obesity treatment: professional, peer, and mentor. Obesity. 2013;21(5):928-934.

13. Shahnazari M, Ceresa C, Foley S, Fong A, Zidaru E, Moody S. Nutritionfocused wellness coaching promotes a reduction in body weight in overweight US veterans. J Acad Nutr Diet. 2013;113(7):928-935.

14. Tucker LA, Cook AJ, Nokes NR, Adams TB. Telephone-based diet and exercise coaching and a weight-loss supplement result in weight and fat loss in 120 men and women. Am J Health Promot. 2008;23(2):121-129.

15. Gabriele JM, Carpenter BD, Tate DF, Fisher EB. Directive and nondirective e-coach support for weight loss in overweight adults. Ann Behav Med. 2011;41(2):252-263.

16. Basak Cinar A, Schou L. Health promotion for patients with diabetes: health coaching or formal health education? Ayse Basak CINAR and lone SCHOU. Int Dent J. 2014;64(1):20-28. 
17. Patja K, Absetz P, Auvinen A, et al. Health coaching by telephony to support self-care in chronic diseases: clinical outcomes from the TERVA randomized controlled trial. BMC Health Serv Res. 2012;10;12(1):147.

18. Temmingh H, Claassen A, van Zyl S, Carrara H, Dayakalashe NM, Myer L, Stein DJ. The evaluation of a telephonic wellness coaching intervention for weight reduction and wellness improvement in a community-based cohort of persons with serious mental illness. J Nerv Ment Dis. 2013;201(11):977-986.

19. Adams SR, Goler NC, Sanna RS, et al. Patient satisfaction and perceived success with a telephonic health coaching program: the Natural Experiments for Translation in Diabetes (NEXT-D) Study, northern California, 2011. Prev Chronic Dis. 2013;10:E179.

20. Mettler EA, Preston HR, Jenkins SM, et al. Motivational improvements for health behavior change from wellness coaching. Am J Health Behav. 2014;38(1):83-91.
21. O’Hara BJ, Phongsavan P, Eakin EG, Develin E, Smith J, Greenaway M, Bauman AE. Effectiveness of Australia's Get Healthy Information and Coaching Service $\AA$ : maintenance of self-reported anthropometric and behavioural changes after program completion. BMC Public Health. 2013;13(1):175.

22. Wolever RQ, Caldwell KL, Wakefield JP, et al. Integrative health coaching: an organizational case study. Explore. 2011;7(1):30-36.

23. Bonal Ruiz R, Almenares Camps HB, Marzán Delis M. Coaching de salud: un nuevo enfoque en el empoderamiento del paciente con enfermedades crónicas no transmisibles [Health Coaching: a new focus on empowering patients with chronic non-communicable diseases]. Medisan. 2012;16(5):773-785. Spanish.

24. Frates EP, Moore MA, Lopez CN, McMahon GT. Coaching for behavior change in physiatry. Am J Phys Med Rehabil. 2011;90: 1074-1082. 


\section{Supplementary material}

Identification

Institution

Characters of the study methodology

- Publication type

Purpose of study issue

Sample

Intervention performed

- Methods employed for intervention of measurement

Results

Implications

- What are the recommendations of the authors
Title of the article:

Main author:

Country:

Language:

Publication year:

Hospital

University

Research center

Single-center study

Multicenter study

Other institutions

Not identifies local

Quantitative approach

Qualitative approach

Literature review

Case report

Others

Size:

Age:

Sex:

Diagnosis:

Inclusion/exclusion criteria of subjects

Figure SI Instrument for data collection based on study by Ursi.'

Note: Copyright ( $)$ 200I-2014. Computer Center of San Carlos Digital Library of Theses and Dissertations of USP. Adapted from Ursi ES. Prevenção de lesões de pele no perioperatório: revisão integrativa da literatura (dissertação). [Prevention of skin lesions in the perioperative: integrative literature review (Dissertation)]. Ribeirão Preto: Universidade de São Paulo, Escola de Enfermagem de Ribeirão Preto; 2005.'

\section{Reference}

1. Ursi ES. Prevenção de lesões de pele no perioperatório: revisão integrativa da literatura (dissertação). [Prevention of skin lesions in the perioperative: integrative literature review (Dissertation)]. Ribeirão Preto: Universidade de São Paulo, Escola de Enfermagem de Ribeirão Preto; 2005. Portuguese.

Diabetes, Metabolic Syndrome and Obesity: Targets and Therapy is an international, peer-reviewed open-access journal committed to the rapid publication of the latest laboratory and clinical findings in the fields of diabetes, metabolic syndrome and obesity research Original research, review, case reports, hypothesis formation, expert opinion and commentaries are all considered for publication. The manuscript management system is completely online and includes a very quick and fair peer-review system, which is all easy to use. Visit http://www.dovepress.com/testimonials.php to read real quotes from published authors.

Submit your manuscript here: https://www.dovepress.com/diabetes-metabolic-syndrome-and-obesity-targets-and-therapy-journal 